\title{
Cellular Mechanism of the Conduction Abnormalities Induced by Serum from Anti-Ro/SSA-positive Patients in Rabbit Hearts
}

\author{
S. Garcia, J. H. M. Nascimento, ${ }^{*}$ E. Bonfa, ${ }^{\star}$ R. Levy, S. F. Oliveira, A. V. Tavares, ${ }^{\star}$ and A. C. Campos de Carvalho \\ Instituto de Biofísica Carlos Chagas Filho, Universidade Federal do Rio de Janeiro, Rio de Janeiro, RJ 21941 Brazil; * Departamento de \\ Biologia Animal, Universidade Federal de Viçosa, Viçosa, MG 36570 Brazil; and ${ }^{\ddagger}$ Disciplina de Reumatologia, Faculdade de Medicina, \\ Universidade de São Paulo, São Paulo, SP 01246 Brazil
}

\section{Abstract}

In this study, IgG fractions from sera of SLE patients with anti-Ro/SSA or anti-Ro/SSA and anti-La/SSB activity were tested in Langendorff preparations of adult rabbit hearts, aiming to reproduce the cardiac manifestations observed in neonatal lupus in an experimental model. The hearts were perfused with normal Tyrode's solution for $\mathbf{3 0} \mathrm{min}$, followed by perfusion with Tyrode's containing $0.3 \mathrm{mg} / \mathrm{ml}$ of anti-Ro $/ \mathrm{SSA}-$ ( or antiRo/La-) positive IgG (nine sera), anti-ribonucleoprotein (RNP)-positive IgG (five sera), or IgG fractions from normal donors (five sera). In one third of the experiments done with anti-Ro/La-positive IgG, heart block was observed. With the remaining fractions, a decrease in heart rate of $17.1 \%$ was observed, but normal sinus rhythm was maintained. The IgG fractions with anti-RNP activity (five experiments) and from normal sera (six experiments) reduced heart rates by 12.9 and $3.3 \%$, respectively, but heart block was not observed.

To further characterize the cellular mechanisms involved in the conduction disturbances observed in the whole rabbit hearts, we conducted experiments with ventricular myocytes isolated from young rabbit hearts, studied by whole cell patchclamp technique. In these experiments, the slow inward currents were analyzed during the superfusion of the cell with normal Tyrode's solution and 5 min after superfusion with Tyrode's solution containing $0.3 \mathrm{mg} / \mathrm{ml}$ of anti-Ro/SSA- (or anti-Ro/La-) positive IgG ( five sera), anti-RNP-positive IgG (three sera), or IgG from normal donors (four sera). Resting and action potential amplitudes were not affected by any of the sera used. The anti-Ro/SSA IgG fraction induced a mean reduction in the peak slow inward current of $31.6 \%$. IgG fractions with anti-RNP activity reduced slow inward current by $4.4 \%$, whereas IgG fractions from normal donors increased this current by $3.3 \%$. IgG-free fractions from sera of patients with anti-Ro/SSA activity did not alter the peak slow inward current.

This work was presented in preliminary form at the Third International Conference on Systemic Lupus Erythematosus in London 1315 April 1992.

Address correspondence to Antonio Carlos Campos de Carvalho, M.D., Ph.D., Instituto de Biofísica Carlos Chagas Filho, Bloco G, Centro de Ciencias da Saúde, Cidade Universitária, Ilha do Fundão, Rio de Janeiro, RJ 21941, Brazil. 1993.

Received for publication 8 March 1993 and in revised form 14 July

J. Clin. Invest.

(C) The American Society for Clinical Investigation, Inc. 0021-9738/94/02/0718/07 \$2.00

Volume 93, February 1994, 718-724
These results show, for the first time, that the presence of anti-Ro/SSA or anti-Ro/SSA and anti-La/SSB antibody activity in IgG fractions from lupus patients' sera can induce cardiac conduction disorders similar to those observed in neonatal lupus. (J. Clin. Invest. 1994. 93:718-724.) Key words: autoimmunity • calcium channels - systemic lupus erythematosus • neonatal lupus $\bullet$ congenital heart block

\section{Introduction}

Ro/SSA and La/SSB are polypeptides associated with small RNA species known as the hY RNAs (1) and RNA polymerase III (2) products, respectively. The functional role of the Ro peptides is still unknown, but the La particle is a transcription termination factor of RNA polymerase III (2). Antibodies to Ro/SSA and La/SSB components of the small nuclear and cytoplasmic ribonucleoproteins are encountered frequently in autoimmune diseases. Among these, the most common are Sjögren's syndrome, SLE, and subacute cutaneous lupus erythematosus (3-6). cDNAs encoding three different Ro peptides have been cloned, with molecular masses ranging from 46 to 60 $\mathrm{kD}$ (7-9), but fusion proteins of only two of these peptides (the 52 and $60 \mathrm{kD}$ ) have been shown to react with anti-Ro-positive sera from SLE and Sjögren's syndrome patients. The cDNA for the La/SSB polypeptide has also been cloned (10) and has been shown to correspond to a $48-\mathrm{kD}$ peptide.

Antibodies to these proteins are found in almost all infants with neonatal lupus erythematosus (NLE) (11). ${ }^{1}$ The syndrome is characterized by a photosensitive cutaneous erythema and, fortunately less frequently, by complete heart block (CHB) (12). The erythema is usually transient (13), whereas the heart block is irreversible in most cases and can lead to intrauterine death (14). Although complete atrial-ventricular (A-V) block is the usual manifestation of cardiac disorder, there have been reports of transient bradycardias and of first and second degree A-V blocks associated with NLE (15-17).

Transplacental transfer of maternal anti-Ro and / or anti-La antibodies has a strong temporal association with the presence of cutaneous lupus in infants with NLE. However, in animal models where such transfer was shown to occur, the skin lesions typical of NLE were not detected, even though deposition of IgG in human skin grafts in the offspring could be clearly demonstrated $(18,19)$. In contrast, the presence of anti-Ro and/or anti-La antibodies in a number of autoimmune disorders in adults is rarely associated with the cardiac conduction disorders observed in infants $(20,21)$. Taken together, these

1. Abbreviations used in this paper: A-V, atrial-ventricular; $\mathrm{CHB}$, complete heart block; EKG, electrocardiogram; $\mathrm{IgG}^{+}$fraction, IgGenriched fraction; $\mathrm{IgG}^{-}$fraction, $\mathrm{IgG}$-depleted fraction; $\mathrm{I}_{\mathrm{si}}$, slow inward current; NLE, neonatal lupus erythematosus; RNP, ribonucleoprotein. 
results indicate that the etiopathogenic mechanisms operating in NLE are poorly understood, albeit the clinically significant correlation between the disease and circulating anti-Ro and / or anti-La autoantibodies.

Until recently, animal models for the cardiac disorders of NLE had not been described. In 1992, Alexander et al. (22) reported a reduction in action potential duration in papillary muscles from newborn rabbit hearts perfused with sera from anti-Ro-positive patients. They further reported that the effect was only present in the IgG-enriched fraction from these sera, that hearts from adult rabbits were unaffected by the anti-Ropositive sera, and that sera from lupus patients with other antibody specificities did not alter action potential duration in newborn rabbit hearts.

Since the complete A-V block is the most common conduction disorder in NLE, we investigated the effects of IgGenriched fractions from anti-Ro- and anti-Ro/La-positive sera in whole hearts from young, adult rabbits perfused by the Langendorff technique. The rationale was that complete A-V blockade is usually associated with conduction failure within the A-V node or in the His's bundle before it branches, and therefore the isolated intact heart seemed a more appropriate animal model in which to study the conduction disorders associated with NLE. The occurrence of A-V block in one third of the experiments where anti-Ro/La-positive sera were used led us to investigate the action of the IgG-enriched fractions from these sera in isolated myocytes dissociated from adult rabbit hearts, studied by the whole cell patch-clamp technique. Our results indicate that IgG-enriched fractions from anti-Ro- (or anti-Ro/La-) positive sera induce a substantial reduction in the slow inward current $\left(I_{\text {si }}\right)$ of the isolated myocytes, suggesting that this may be the cellular mechanism responsible for the $\mathrm{A}-\mathrm{V}$ block detected in the intact hearts.

\section{Methods}

Sera. All sera were obtained from SLE patients who fulfilled four or more criteria of the American Rheumatology Association (23). Patients were observed at the Rheumatology Clinic at the University of São Paulo or at the High Risk Pregnancy Clinic at the Pediatrics Institute of the Federal University of Rio de Janeiro. None of the patients had infants with CHB, although one anti-Ro/SSA-positive mother had a baby with a transient bradycardia ( patient 7 in Table II). Control sera were obtained from voluntary normal donors. The control sera tested negative for anti-native DNA, ribonucleoprotein (RNP), Sm, cardiolipin, ribosomal $\mathrm{P}$ protein, Ro/SSA, and La/SSB activity.

Autoantibody analysis. All sera were tested by indirect immunofluorescence using mouse livers (24) and Clostridium luciliae (25) as substrates for the detection of anti-nuclear and anti-native DNA antibodies, respectively. Anti-Ro/SSA, La/SSB, Sm, and RNP antibodies were detected by counterimmunoelectrophoresis, using dog spleen saline extract as the source of antigen (26). Reference sera, with known specificities, were used to characterize the precipitating antibodies in each tested serum. The presence of anticardiolipin antibodies was tested by a standardized ELISA method (27) and anti-ribosomal P antibodies by Western blotting (28). For the present study, we selected 1 anti-Ro/SSA- and anti-La/SSB-positive serum, 10 anti-Ro/SSApositive monospecific sera, 8 anti-RNP-positive monospecific sera, and 9 control sera from normal donors.

Fractionation of the sera. All sera were precipitated by treatment with saturated ammonium sulfate for $90 \mathrm{~min}$ on ice, followed by centrifugation at $10,000 \mathrm{rpm}$ for $30 \mathrm{~min}$. The pellet was resuspended in a Tris-buffered saline ( $20 \mathrm{mM}$ Tris, $150 \mathrm{mM} \mathrm{NaCl}, \mathrm{pH} 8.0$ ), and IgG was purified by protein $\mathrm{A} /$ Sepharose gel separation. In addition, the IgG-depleted $\left(\mathrm{IgG}^{-}\right)$fraction was collected. IgG-enriched $\left(\mathrm{IgG}^{+}\right)$and $\mathrm{IgG}^{-}$fractions were then dialyzed against calcium-free Tyrode's solution (mM: $\mathrm{NaCl} 137$, glucose 6, $\mathrm{NaHCO}_{3} 12, \mathrm{KCl} 2.7, \mathrm{Na}_{2} \mathrm{HPO}_{4} 1.8$, and $\mathrm{MgCl}_{2} \mathbf{0 . 5}$; to obtain Ca-containing Tyrode's, $2.7 \mathrm{mM} \mathrm{CaCl}_{2}$ was added) overnight at $4^{\circ} \mathrm{C}$. After dialysis, protein concentration in the fractions was determined by the Bradford method (29), and the purity of the fractions was evaluated by immunodiffusion against human anti-total Ig, anti-IgG, and anti-albumin (Cappel, Durham, NC).

Electrocardiogram (EKG) recordings in isolated rabbit hearts. Adult rabbits weighing $\sim 1,800 \mathrm{~g}$ were killed by cervical dislocation. Their hearts were rapidly removed and cannulated through the aorta for continuous perfusion of the coronary system with Tyrode's solution at $37^{\circ} \mathrm{C}$. After rinsing all the blood from the coronary circulation, the heart was lowered into a beaker containing prewarmed Tyrode's solution. Three glass electrodes, filled with $1 \mathrm{M} \mathrm{NaCl}$, were then positioned inside the beaker to obtain optimal electrocardiographic recordings. Two of the electrodes were connected to the differential inputs of an amplifier (3A-9; Tektronix Inc., Beaverton, OR), and the third was connected to ground. Recordings were displayed on an oscilloscope (565; Tektronix Inc.) and on a two-channel chart-recorder (model 2200; Gould Inc., Glen Burnie, MD). Experimental protocol consisted of taking control records for $30 \mathrm{~min}$ in Tyrode's, at least a 30 -min perfusion period with Tyrode's containing $0.3 \mathrm{mg} / \mathrm{ml}$ of the $\mathrm{IgG}^{+}$fraction being tested, and a return to Tyrode's for variable periods.

Patch-clamp recordings in isolated cardiac myocytes. Isolated ventricular myocytes were obtained by collagenase digestion of young rabbit hearts, as described previously (30). Rod-shaped cells, with well defined striations and without sarcolemmal blebs, were selected for electrophysiological studies under a Nikon Diaphot inverted microscope equipped with differential interference contrast. Cells were continuously superfused with Tyrode's solution at room temperature.

Patch electrodes were fabricated in a two-stage puller (L/M 3P-A, patch pipette puller; List-Electronic, Darmstadt, Germany) and were filled with $120 \mathrm{mM} \mathrm{KCl}, 0.5 \mathrm{mM} \mathrm{CaCl}_{2}, 11 \mathrm{mM} \mathrm{EGTA} / \mathrm{NaOH}, 9 \mathrm{mM}$ $\mathrm{NaCl}, 2 \mathrm{mM} \mathrm{MgCl}$, and $10 \mathrm{mM}$ Hepes, $\mathrm{pH}$ 7.2. Resistance of the electrodes in this solution ranged from 4 to $6 \mathrm{M} \Omega$. A patch-clamp amplifier (EPC-7; List-Electronic) was used to study the electrophysiological properties of the isolated myocytes under the whole cell patchclamp technique (31). After seal formation and rupture of the membrane patch, resting and action potential amplitudes were routinely recorded in current-clamp mode. Resting potentials ranged in amplitude between -90 and $-85 \mathrm{mV}$. Action potential amplitudes ranged from 115 to $125 \mathrm{mV}$.

Voltage-clamp protocols and data acquisition were controlled by an IBM-compatible 286 computer running pClamp software (Axon Instruments, Inc., Foster City, CA), interfaced to the amplifier by an 80-kHz Labmaster board (Scientific Solutions Inc., Solon, OH). Cells were clamped at a holding potential of $-40 \mathrm{mV}$ to inactivate fast sodium currents and T-type calcium currents, and a standard protocol consisting of 1 hyperpolarizing and 12 depolarizing pulses, each lasting for $370 \mathrm{~ms}$, was delivered to the cell, driving its membrane potential from -50 to $+70 \mathrm{mV}$. The interpulse interval was set at $10 \mathrm{~s}$ to allow for complete recovery of inactivating calcium currents. The experimental protocol consisted of running two complete pulse protocols in Tyrode's, separated by a 5-min interval. If the $I_{s i}$ was stable, without evidence of run down, we proceeded to superfuse the cells with Tyrode's solution containing $0.3 \mathrm{mg} / \mathrm{ml}$ of the IgG fraction to be tested. Current records were then taken at 1 and $5 \mathrm{~min}$ after this solution had reached the cells, and usually $5 \mathrm{~min}$ after returning to Tyrode's. Stored data were analyzed using Clampan to generate I-V curves where the peak $I_{s i}$ was plotted versus clamp potential. Because of the small amplitudes of the transient outward and calcium-dependent potassium currents and the virtual absence of the delayed rectifying potassium current in rabbit ventricular myocytes (32), we assume that the peak $I_{s i}$ (measured in the presence of $\mathrm{K}^{+}$in the pipette solution as the difference between the holding current and the peak current at each clamp potential) is composed mainly of L-type inward calcium current. 
$\underline{A}$

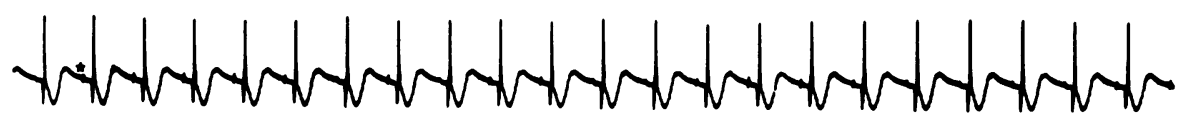

B

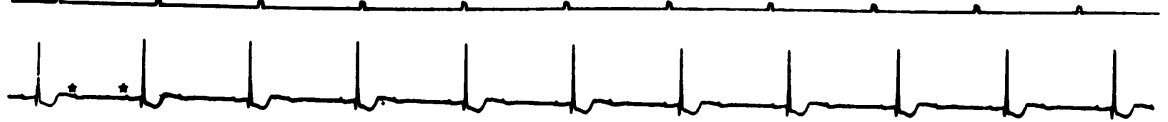

C

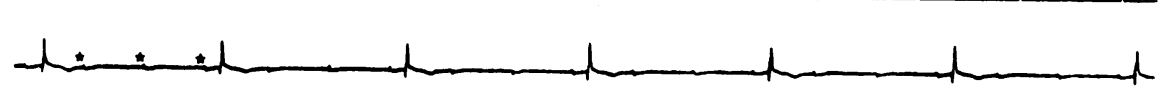

Figure 1. Anti-Ro/SSA IgG induces conduction blockade in whole rabbit hearts. EKG recorded during perfusion with normal Tyrode's solution $(A)$. The rhythm is regular and the rate is $120 \mathrm{bpm}$. A recording obtained $10 \mathrm{~min}$ after starting the perfusion with $0.3 \mathrm{mg} / \mathrm{ml}$ anti-Ro/SSA-positive IgG in normal Tyrode's solution is shown in $B$. A 2:1 second degree A-V block can be observed. This block was not reversed $11 \mathrm{~min}$ after returning to normal Tyrode's solution, as illustrated in $C$, when in fact the conduction disturbance evolved to a 3:1 A-V block. The frequency of $P$ waves was 110 and $100 \mathrm{bpm}$ in $B$ and $C$, respectively. The stars in all records identify the $P$ waves. Time marks on top of each record are spaced at $1-s$ intervals.

\section{Results}

Anti-Ro/SSA induced conduction disturbances in whole hearts. The most common cardiac conduction disorders associated with NLE involve the specialized tissues of the heart. Thus, EKG recording of the electrical activity of whole hearts, perfused by the Langendorff technique, constitutes an adequate, simple, and rapid method to screen the arrhythmogenic effects of anti-Ro/SSA- (or anti-Ro/SSA- and anti-La/SSB-) positive sera.

Fig. 1 illustrates the effect of perfusing isolated rabbit hearts with $\mathrm{IgG}^{+}$from a Ro/SSA-positive serum. The EKG recorded in Tyrode's shows a regular sinus rhythm with a 120 beats per minute (bpm) rate (Fig. $1 \mathrm{~A}) .10 \mathrm{~min}$ after starting the perfusion with $0.3 \mathrm{mg} / \mathrm{ml}$ anti-Ro/SSA-positive $\mathrm{IgG}^{+}$in Tyrode's solution, a 2:1 second degree A-V block ensued (Fig. $1 \mathrm{~B}$ ). Frequency of $P$ waves was $110 \mathrm{bpm}$. $11 \mathrm{~min}$ after returning to normal Tyrode's solution, the A-V block was not reversed and progressed to a 3:1 block that was maintained for another 10 min before ending the experiment (Fig. $1 C$ ). Frequency of $\mathrm{P}$ waves decreased to $100 \mathrm{bpm}$.

The results from 15 other experiments done with one anti$\mathrm{Ro} / \mathrm{La}-$ and eight anti-Ro-positive $\mathrm{IgG}^{+}$sera are listed in the

Table I. EKG in Rabbit Hearts Perfused with Different IgG Fractions by the Langendorff Technique

\begin{tabular}{lccc}
\hline \multicolumn{1}{c}{ IgG } & $\begin{array}{c}\text { Number of } \\
\text { experiments }\end{array}$ & $\begin{array}{c}\text { A-V } \\
\text { block }\end{array}$ & $\begin{array}{c}\text { Average frequency } \\
\text { reduction } \\
( \pm S D)\end{array}$ \\
\hline \multicolumn{1}{c}{$n$} & & & $\%$ \\
Anti-Ro (9) & 15 & 5 & $17.1 \pm 7.4$ \\
Anti-RNP* (5) & 5 & - & $12.9 \pm 7.7$ \\
Normal (5) & 6 & - & $3.3 \pm 7.6$ \\
\hline
\end{tabular}

Columns, from left to right, describe the type of IgG fraction tested, the number of experiments performed with each type of IgG, the number of experiments where A-V block was detected, and the average reduction in sinus node frequency $\pm \mathrm{SD}$. $(n)$, the number of different IgG fractions tested for each IgG type. * Experiments performed with pooled monospecific sera with anti-RNP activity. first row of Table I. In five experiments, one anti-Ro/La- and two anti-Ro-positive sera induced second or third degree A-V block. In the remaining experiments, we observed a decrease in beat rate, but normal sinus rhythm and the P-R interval were maintained. Table II lists individually all patients' sera used (one anti-Ro/La [ patient 8] and eight anti-Ro), the number of experiments done with each serum, the sera that induced the $\mathrm{A}-\mathrm{V}$ block, and the mean decrease in beat rate obtained with each serum in those experiments where there was no conduction block. Sera from patients 6,7 , and 8 induced A-V block, but blockade was not always observed, even with different serum samples from the same patient. Since all three samples of sera from patients 6 and 7 used in the experiments were collected at different times, this may be the reason for the variability in the blockade.

Table II. EKG in Rabbit Hearts Perfused with Anti-Ro/SSApositive $\operatorname{Ig} G$

\begin{tabular}{lccc}
\hline Patient & $\begin{array}{c}\text { Number of } \\
\text { experiments }\end{array}$ & $\begin{array}{c}\text { A-V } \\
\text { block* }\end{array}$ & $\begin{array}{r}\text { Heart rate } \\
\text { reduction }\end{array}$ \\
\hline & & & $\%$ \\
1 & 1 & - & 27.5 \\
2 & 1 & - & 15.1 \\
3 & 1 & - & 13.3 \\
4 & 1 & - & 20.6 \\
5 & 1 & $2(3.7 \%)$ & 14.5 \\
6 & 3 & $2(0.8 \% ; 3.6 \%)$ & 25.3 \\
7 & 3 & - & 19.5 \\
$8^{\ddagger}$ & 2 & & - \\
9 & 2 & & 16.3 \\
& & & \\
\hline
\end{tabular}

Columns, from left to right, describe the number of different patients' sera tested, the number of experiments done with each patient's serum, the number of experiments where A-V block was detected with each patient's serum, and the percentage of reduction in heart rate in those experiments where A-V block was not detected. * In brackets is the percent $P$ wave frequency reduction for each experiment where A-V block was observed. ${ }^{\ddagger}$ Patient was anti-Ro/SSAand anti-La/SSB-positive. 
Table I also lists results obtained with five anti-RNP-positive $\mathrm{IgG}^{+}$and five normal $\mathrm{IgG}^{+}$( fractions obtained from normal donors). In five experiments done with the RNP-positive and six done with the normal sera $\mathrm{IgG}^{+}$no A-V block was detected. Sinus rhythm and P-R interval were maintained, but beat rate decreased by 12.9 and $3.3 \%$, respectively. Statistical analysis using unpaired Student's $t$ tests indicates that the reduction in frequency obtained in the two groups is not significantly different $(P=0.068)$. When the same statistical treatment is applied to the anti-Ro/SSA versus normal group, the reduction in beat rate is significantly different between the two groups $(P=0.001)$, but not between the anti-Ro/SSA versus anti-RNP groups $(P=0.29)$.

Slow inward currents are inhibited by anti-Ro/La-positive sera in isolated myocytes. To gain a better insight into the cellular mechanisms involved in the arrhythmogenic effects of antiRo/La-positive sera, we decided to study the effects of these sera in isolated myocytes from young rabbit hearts by the whole cell patch-clamp technique. Resting and action potential amplitudes were not altered by superfusion of the myocytes with anti-Ro/La-positive, anti-RNP-positive, or normal sera. These results and those of Alexander et al. (22) suggest that inward sodium currents are not affected by these sera. The A-V blockade reported in this paper and the reduction in action potential duration in neonatal rabbit hearts reported previously (22) could be consequences of a decrease in $\mathrm{I}_{\mathrm{si}}$. To examine this possibility, we clamped the cells at $-40 \mathrm{mV}$ holding potential, thus inactivating the fast inward sodium current and T-type calcium current, and applied the pulse protocol described in Methods.

Fig. 2 is an I-V plot of peak $I_{s i}$ versus clamp potential obtained in normal Tyrode's (open circles), and 5 min after superfusion of the cell with $0.3 \mathrm{mg} / \mathrm{ml}$ anti-Ro/SSA-positive $\mathrm{IgG}^{+}$in Tyrode's solution (open triangles). The IgG fraction induced a marked reduction in the peak $\mathrm{I}_{\mathrm{si}}$, which was not reversible on return to Tyrode's (not shown). The similar shape of the two curves indicates that voltage dependence of the current was not significantly altered. The inset shows the two families of current curves obtained under these conditions. The time to reach peak inward current was not changed by the Ro/SSA-positive $\mathrm{IgG}^{+}$. At the highest clamp potentials, a slight increase in the outward current can be observed in the $\mathrm{IgG}^{+}$record, which may be related to the reduced inward calcium current. Fig. 3 shows that neither anti-RNP-positive $(A)$

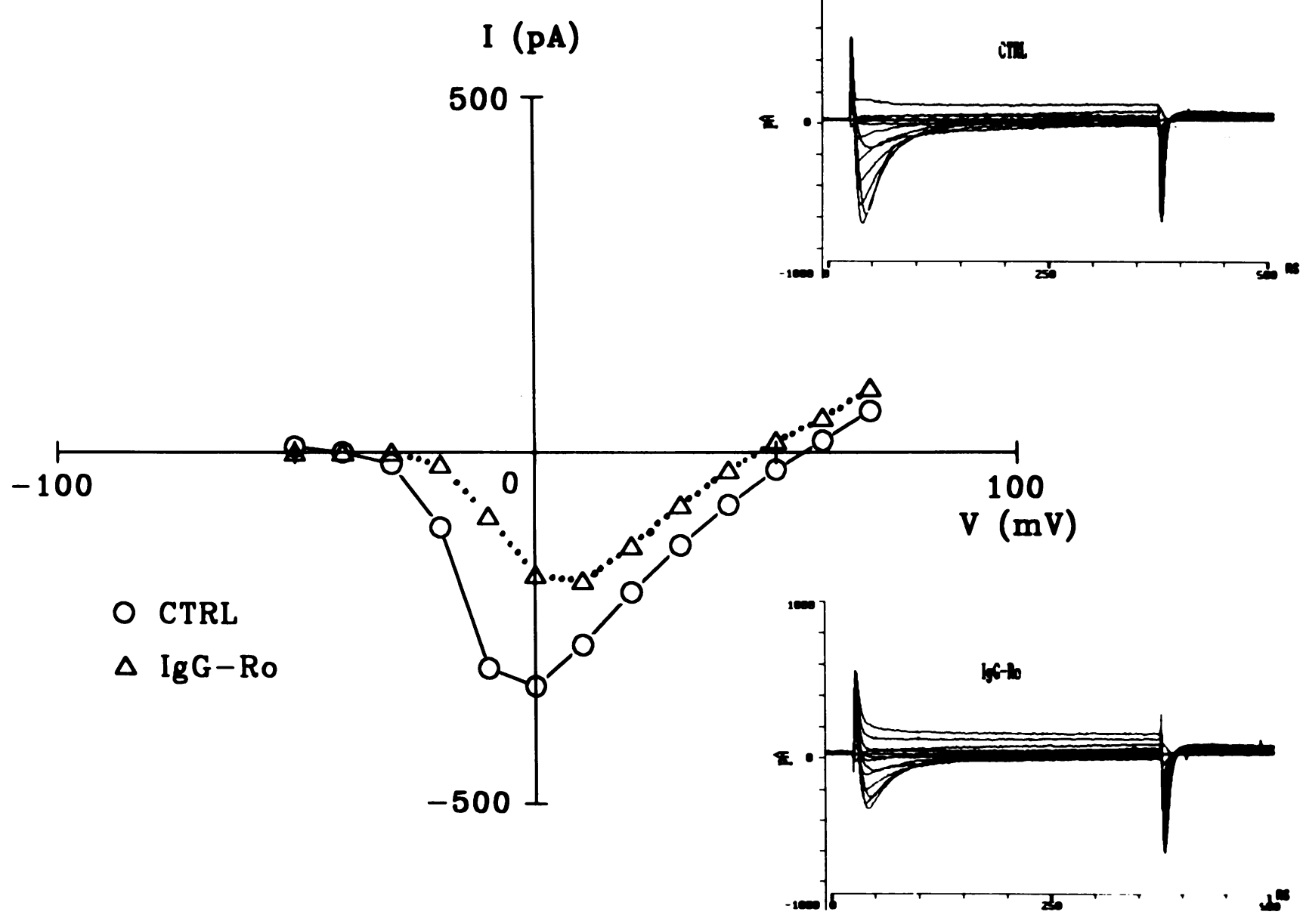

Figure 2. Anti-Ro/SSA IgG blocks $\mathrm{I}_{\mathrm{si}}$ in isolated myocytes from rabbit heart. $\mathrm{I}-\mathrm{V}$ plot of peak $\mathrm{I}_{\mathrm{si}}$ versus clamp potential. (Open circles) Values of peak $I_{\mathrm{si}}$ during the perfusion with normal Tyrode's solution. (Open triangles) Values obtained $5 \mathrm{~min}$ after superfusion of the cell with $0.3 \mathrm{mg} / \mathrm{ml}$ anti-Ro/SSA-positive IgG in normal Tyrode's solution. A marked reduction in peak $I_{s i}$ can be observed. The inset shows current versus time records obtained at the various clamp potentials during perfusion with normal Tyrode's (upper record) and 5 min after superfusion with antiRo/SSA IgG (lower record). 
A

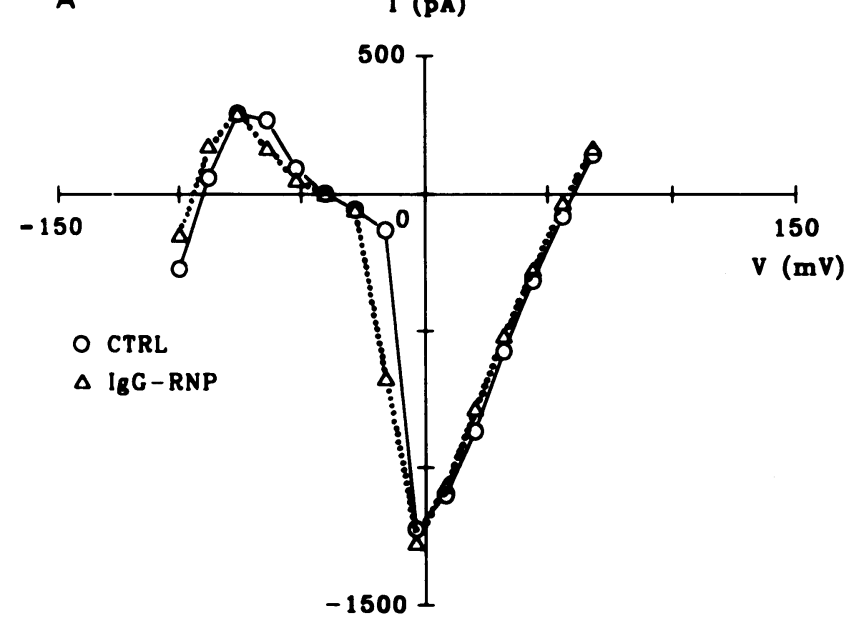

B

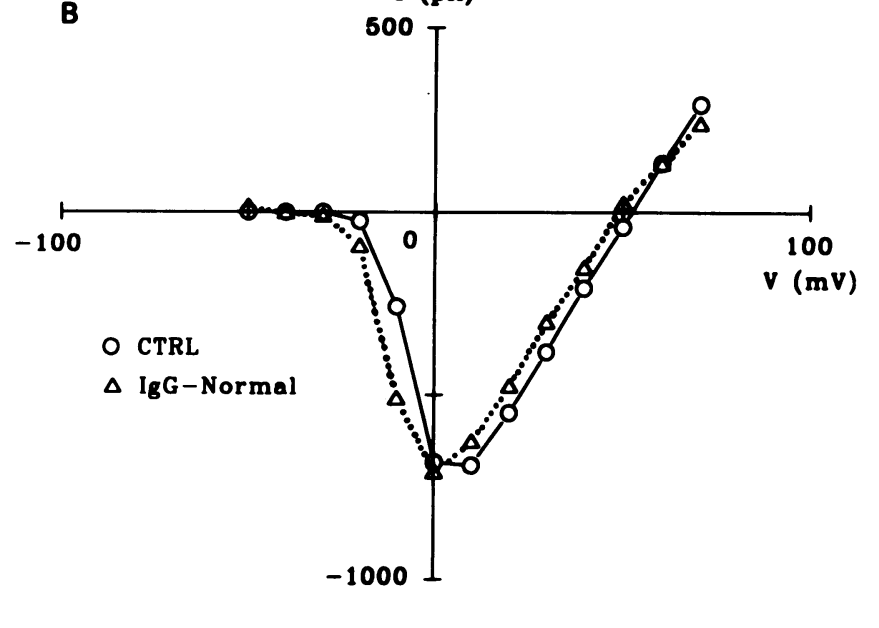

Figure 3. Anti-RNP and normal IgGs do not affect $\mathrm{I}_{\mathrm{si}}$ in isolated myocytes. $\mathrm{I}-\mathrm{V}$ plot of peak $\mathrm{I}_{\mathrm{si}}$ versus clamp potential. (Open circles) Values of peak $\mathrm{I}_{\mathrm{si}}$ during the perfusion with normal Tyrode's solution. (Open triangles) Values obtained 5 min after superfusion of the myocytes with 0.3 $\mathrm{mg} / \mathrm{ml}$ anti-RNP $\operatorname{IgG}(A)$ and $0.3 \mathrm{mg} / \mathrm{ml}$ normal $\operatorname{IgG}(B)$ in normal Tyrode's solution. No reduction in peak $\mathrm{I}_{\mathrm{si}}$ can be observed in either case. Pulse protocol was changed slightly in $A$, clamping the membrane potential from -100 to $+62 \mathrm{mV}$ and thus allowing observation of the inwardly rectifying potassium current.

nor normal $(B) \mathrm{IgG}^{+}$, at $0.3 \mathrm{mg} / \mathrm{ml}$ in Tyrode's, reduced the peak $\mathrm{I}_{\mathrm{si}} \mathrm{s}$. In obtaining the I-V plot for Fig. $3 \mathrm{~A}$, a slightly different pulse protocol was used, clamping the membrane potential of the myocyte from -100 to $+62 \mathrm{mV}$, from a holding of -40 $\mathrm{mV}$. Fig. 4 illustrates the effects of $\mathrm{IgG}^{+}$and $\mathrm{IgG}^{-}$fractions of the same anti-Ro/SSA-positive serum on two isolated myocytes. After the control measurement (open circles), the cell was superfused for $5 \mathrm{~min}$ with the $\mathrm{IgG}^{+}$fraction and a marked reduction in peak $\mathrm{I}_{\mathrm{si}}$ was observed (open triangles) (Fig. $4 \mathrm{~A}$ ). Superfusion with Tyrode's solution containing $1 \mathrm{mM} \mathrm{CdCl}$ (open squares), a specific blocker of inward calcium currents, led to an almost complete block of the $I_{\text {si }}$, and demonstrates the very small contribution of outward currents in ventricular rabbit myocytes under our experimental conditions. The $\mathrm{IgG}^{-}$ fraction of anti-Ro/SSA-positive sera did not reduce the amplitude of the $I_{s i}$, as shown in Fig. $4 B$.

Table III summarizes all the results obtained in the isolated myocytes. One anti-Ro/SSA and anti-La/SSB and four antiRo/SSA-positive $\mathrm{IgG}^{+}$fractions were tested in 12 cells, resulting in a mean decrease in the peak $\mathrm{I}_{\mathrm{si}}$ of $31.6 \%$. Three anti-RNP $\mathrm{IgG}^{+}$fractions were tested in six myocytes, and the mean reduction in peak $\mathrm{I}_{\mathrm{si}}$ was $4.4 \%$. Four $\mathrm{IgG}^{+}$fractions from normal

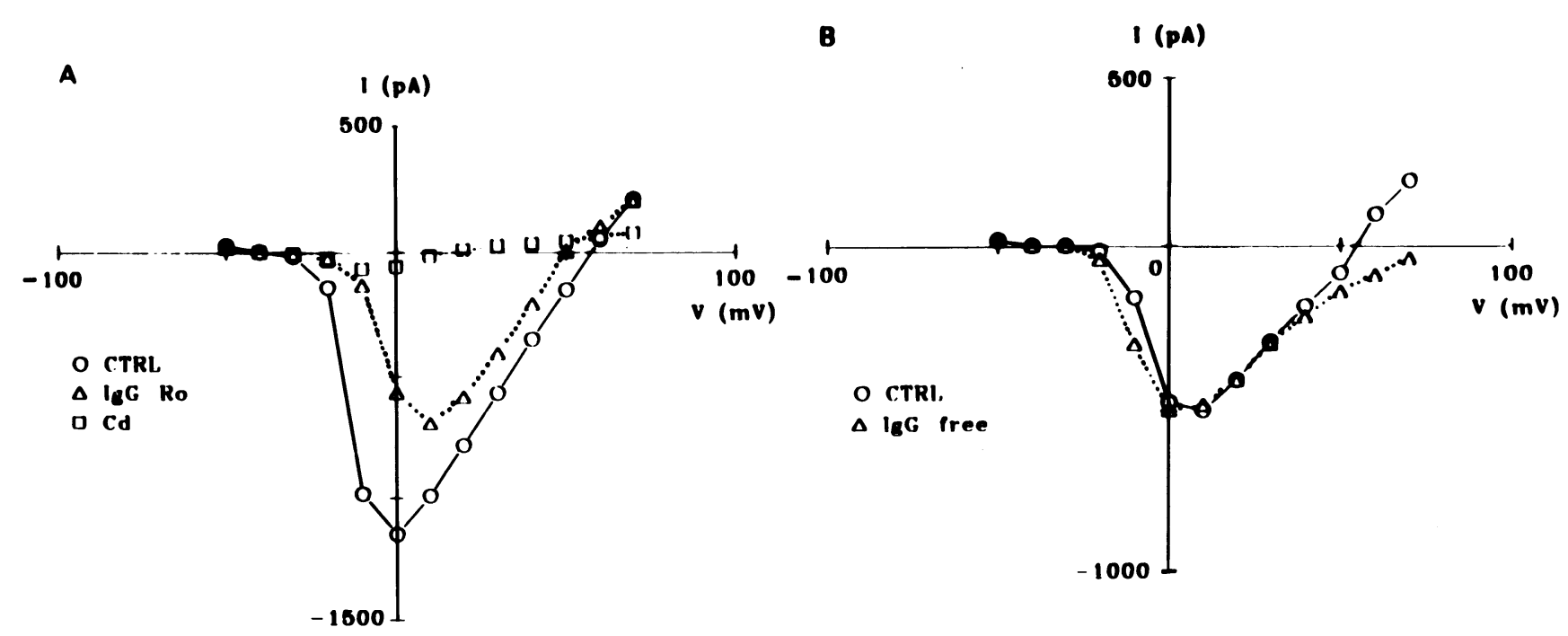

Figure 4. Reduction of peak $\mathrm{I}_{\mathrm{si}}$ by $\mathrm{IgG}^{+}$and not by IgG-free fractions of anti-Ro/SSA-positive sera. I-V plot of peak $\mathrm{I}_{\mathrm{si}}$ versus clamp potential. (Open circles) Values of peak $I_{\mathrm{si}}$ during the perfusion with normal Tyrode's solution. (Open triangles) Values obtained 5 min after superfusion of the myocytes with $0.3 \mathrm{mg} / \mathrm{ml}$ anti-Ro/SSA-positive $\operatorname{IgG}^{+}(A)$ or IgG-free $(B)$ fraction. A marked reduction in the peak $\mathrm{I}_{\mathrm{si}}$ is observed with the $\mathrm{IgG}^{+}$fraction, while the IgG-free fraction of the same serum does not affect $\mathrm{I}_{\mathrm{si}}(B)$. In $A$, open squares represent the transmembrane current obtained during superfusion with normal Tyrode's solution containing $1 \mathrm{mM} \mathrm{CdCl}$. This calcium channel blocker produced an almost complete block in the transmembrane current recorded, indicating the L-type calcium current is the main component of the $I_{s i}$ and that outward currents have a very small amplitude under our experimental conditions $(-40 \mathrm{mV}$ holding potential $)$. 
Table III. Electrophysiological Studies of Isolated Myocytes by the Patch-clamp Technique

\begin{tabular}{lccc}
\hline \multicolumn{1}{c}{ IgG } & $\begin{array}{c}\text { Number } \\
\text { of sera studied }\end{array}$ & $\begin{array}{c}\text { Number } \\
\text { of cells }\end{array}$ & $\begin{array}{c}\text { Percent variation } \\
\text { of peak } \mathrm{I}_{\mathbf{s i}}\end{array}$ \\
\hline Anti-Ro & 5 & 12 & $-31.6 \pm 23.9$ \\
Anti-RNP & 3 & 6 & $-4.4 \pm 10.4$ \\
Normal & 4 & 5 & $+3.0 \pm 12.8$ \\
\hline
\end{tabular}

Columns, from left to right, describe the type of IgG fraction tested, the number of different sera used, the total number of cells studied for each IgG type, and the percent of variation in the peak $I_{\text {si }}$ (measured $5 \mathrm{~min}$ after beginning the perfusion with the IgG fraction) \pm SD.

sera were used on five cells, increasing peak $\mathrm{I}_{\mathrm{si}}$ by a mean value of $3.0 \%$. Statistical analysis of the data using unpaired Student's $t$ tests indicates that the percentage of variation obtained in the anti-Ro/SSA-positive $\mathrm{IgG}^{+}$group is significantly different from both the $\mathrm{IgG}^{+}$normal $(P=0.009)$ and the $\mathrm{IgG}^{+}$ anti-RNP-positive group $(P=0.018)$.

\section{Discussion}

In this paper we show for the first time that the cardiac conduction disorders associated with NLE can be reproduced in an animal model. The occurrence of conduction blockade and $\mathrm{I}_{\mathrm{si}}$ reduction when using either monospecific anti-Ro/SSA or anti-Ro/SSA and anti-La/SSB sera suggests that the anti-La activity is not essential for the observed effects.

Aside from a reduction in beat rate, also detected with $\mathrm{IgG}^{+}$ from-anti-RNP-positive and normal sera, in one-third of the experiments done using anti-Ro/La-positive sera we observed varying degrees of A-V block, most likely attributable to conduction disturbances within the A-V node. This result has important implications with regard to the etiopathogenesis of NLE, and in more general terms to the pathological role of autoantibodies in autoimmune diseases. It suggests that the presence of anti-Ro/SSA antibodies may be sufficient to induce the $\mathrm{CHB}$, and that the presence of other components of the immunological response repertoire may not be essential for the primary effect. The fact that all sera, and sometimes sera obtained at different times from the same patient, did not produce the blockade deserves further studies. This variability is similar to that found in human NLE where disease expression may differ even in siblings (33). It remains unclear at present whether the pathogenic antibody is a subpopulation of antiRo/SSA or another antibody specificity linked to anti-Ro/ SSA. The use of affinity-purified anti-Ro/SSA antibodies in these experiments should help resolve this issue and, more importantly, should establish a definite relation between anti-Ro/ SSA antibody activity and cardiac conduction blockade.

Conduction in the A-V node is essentially dependent on calcium electrogenesis. Thus, A-V block is expected to result from treatments leading to reduction of the $\mathrm{I}_{\mathrm{si}}$. Therefore, our results in the isolated ventricular myocytes correlate well with the observations at the whole heart level, since the L-type calcium channel is mainly responsible for $\mathrm{I}_{\mathrm{si}}$ in ventricular myocytes and for the propagation of the action potential in the A-V node. We have not detected significant alterations in outward currents during superfusion with any of the sera. However, the small amplitude or virtual absence of many components of the potassium outward currents in ventricular myocytes from rabbit hearts (32) precludes a precise analysis. At any rate, the rabbit heart is certainly a better model for the human cardiac electrogenesis than the rat heart, where transient outward current is very pronounced (34). The observation that resting and action potential amplitudes were also not affected by any of the sera used is in agreement with the report of Alexander et al. (22). These investigators have shown that resting potential and the maximum derivative of the upstroke of the action potential were not changed significantly by the presence of the anti-Ro-positive sera. Taken together, these results suggest that neither sodium nor inward rectifying potassium currents are affected by the anti-Ro/SSA-positive $\mathrm{IgG}^{+}$. Thus, the effect on the $\mathrm{I}_{\mathrm{si}}$ seems to be quite specific and qualitatively explains our result ( $\mathrm{A}-\mathrm{V}$ block) and that of Alexander et al. ( shortening of the action potential duration in neonatal rabbit hearts).

The lack of effect of the anti-Ro/SSA-positive sera reported by Alexander et al. (22) when using adult papillary muscle from rabbit hearts appears to contrast with our results in isolated myocytes from the same species. However, it is important to note that a clear distinction must be made between effects observed in isolated myocytes and those observed using muscle bundles, where coupling between cells contributes a source of current to reduce variations in the membrane potential of the impaled cell. Also, the sensitivity of the isolated cell studies is further amplified by the voltage-clamp conditions used here, where the major inward current activated is the Ltype calcium current. Increased action potential duration is characteristic of the neonatal heart $(22,34)$. Therefore, it is not surprising that the effects seen by Alexander et al. were more pronounced in the neonatal than in the adult papillary muscle.

The short latency effect of the anti-Ro-positive $\mathrm{IgG}^{+}$favors a direct interaction with an antigenic site at the sarcolemma. Under some circumstances, keratinocytes express the Ro/SSA protein at the cell surface membrane $(35,36)$ in addition to its normal intracellular localization. Immunocytochemistry of newborn papillary muscles showed positive staining with antiRo/SSA-positive affinity-purified serum in some cells, although membrane localization could not be demonstrated (22). Even if the Ro protein is expressed at the surface membrane it is not clear how the antibody-antigen interaction might affect the calcium channels. Nonspecific cell deterioration, leading to increased intracellular calcium concentration (which is known to inactivate calcium current), is unlikely because resting potentials, action potential amplitudes, and input resistances of the cells were not affected. That the voltage dependence and the time to reach peak $I_{s i}$ were not altered significantly by the anti-Ro/SSA-positive $\mathrm{IgG}^{+}$suggests a blocking effect by reduction of the total number of calcium channels available to open. The reduction in the number of functional calcium channels as a result of a nonspecific hindrance effect at the channel mouth because of anti-Ro/SSA antibody Ro-antigen interaction is highly unlikely because other channel types would be expected to also be affected. The simplest explanation is a direct interaction between the antiRo/SSA antibody and the calcium channel protein. IgG from patients with the Lambert-Eaton syndrome has been shown to block L-type calcium channels in bovine adrenal chromaffin cells in a rather specific way (37).

One of the three reported cDNA clones for the Ro/SSA peptides is highly homologous to rabbit calreticulin (38), a high affinity calcium-binding protein of the endoplasmic reticu- 
lum (39), suggesting the possibility that Ro/SSA and calcium channel proteins might share epitopes as well. Although calreticulin and Ro/SSA probably are not members of the same protein family (40), antibodies to calreticulin have been found in SLE patients (41). The recent cloning of the Ro antigens combined with the results reported here strongly indicate that testing the effect of antibodies specific for the 46-, 52-, and 60-kD Ro peptides in isolated myocytes will yield increased insight into the molecular mechanisms underlying the effects of the anti-Ro-positive $\mathrm{IgG}^{+}$in the blockade of the L-type cardiac calcium channel.

\section{Acknowledgments}

This work was supported by grants from FINEP (to A.C. Campos de Carvalho) and FAPESP (92/2943-1, to E. Bonfa). S. Garcia, R. Levy, and S.F. Oliveira were fellows of CAPES and CNPq. A.C. Campos de Carvalho is a senior career investigator of CNPq.

\section{References}

1. Ben-Chetrit, E., B. J. Gandy, E. M. Tan, and K. F. Sullivan. 1989. Isolation and characterization of $\mathrm{cDNA}$ clone encoding the $60-\mathrm{kD}$ component of the human SS-A/Ro ribonucleoprotein autoantigen. J. Clin. Invest. 83:1284-1292.

2. Bachmann, M., K. Pfeifer, H. C. Schröder, and W. E. G. Müller. 1990. Characterization of the autoantigen $\mathrm{La}$ as a nucleic acid-dependent ATPase/ dATPase with melting properties. Cell. 60:85-93.

3. Mayet, W. J., M. Bachmann, K. Pfeifer, H. C. Schröder, W. E. G. Müller, W. Gudat, G. W. Korting, and K. H. M. Z. Buschenfelde. 1988. A monoclonal Ro-antibody and the serum of a Ro-positive patient with subacute cutaneous lupus erythematosus (SCLE) react with basal layers of human epidermis. Eur. $J$. Clin. Invest. 18:465-471.

4. Sontheimer, R. D., and D. P. McCauliffe. 1990. Pathogenesis of anti-Ro/ SS-A autoantibody-associated cutaneous lupus erythematosus. Dermatologic Clinics. 8:751-758.

5. Meilof, J. F., I. Bantjes, J. De Jong, A. P. Van Dam, and R. J. T. Smeenk. 1990. The detection of anti-Ro/SS-A and anti-La/SS-B antibodies. A comparison of counterimmunoelectrophoresis with immunoblot, ELISA, and RNA-precipitation assays. J. Immunol. Methods. 133:215-226.

6. Boire, G., F. J. Lopes-Longo, S. La Pointe, and H. Ménard. 1991. Sera from patients with autoimmune disease recognize conformational determinants on the 60-kD Ro/SS-A protein. Arthritis Rheum. 34:722-730.

7. McCauliffe, D. P., F. A. Lux, T.-S. Lieu, I. Sanz, J. Hanke, M. M. Newkirk, L. L. Bachinski, Y. Itoh, M. J. Siciliano, M. Reichlin et al. 1990. Molecular cloning, expression, and chromosome 19 localization of human Ro/SS-A autoantigen. J. Clin. Invest. 85:1379-1391.

8. Chan, E. K. L., J. C. Hamel, J. P. Buyon, and E. M. Tan. 1991. Molecular definition and sequence motifs of the $52-\mathrm{kD}$ component of human SS-A/Ro autoantigen. J. Clin. Invest. 87:68-76.

9. Deutscher, S. L., J. B. Harley, and J. D. Keene. 1988. Molecular analysis of the 60-kDa human Ro ribonucleoprotein. Proc. Natl. Acad. Sci. USA. 85:94799483.

10. Chambers, J. C., D. Kenan, B. J. Martins, and J. D. Keene. 1988. Genomic structure and amino acid sequence domains of the human La autoantigen. $J$. Biol. Chem. 263:18043-18051.

11. Miyagawa, S., K. Dohi, A. Yoshioka, and T. Shiarai. 1990. Female predominance of immune response to SS-A/Ro antigens and risk of neonatal lupus erythematosus. Br. J. Dermatol. 123:223-227.

12. Watson, R. M., B. L. Braunstein, A. J. Watson, M. C. Hochberg, and T. T. Provost. 1986. Fetal wastage in women with anti-Ro (SSA) antibody. J. Rheumatol. 13:90-94.

13. McCune, A. B., W. L. Weston, and L. A. Lee. 1987. Maternal and fetal outcome in neonatal lupus erythematosus. Ann. Intern. Med. 106:518-523.

14. Buyon, J. P., and R. Wincherter. 1990. Congenital complete heart block. A human model of passively acquired autoimmune injury. Arthritis Rheum. 33:609-614.

15. McCue, C. M., M. E. Mantakas, J. B. Tingelstad, and S. Ruddy. 1977. Congenital heart block in newborns of mothers with connective tissue disease. Circulation. 56:82-90.

16. Esscher, E., and J. S. Scott. 1979. Congenital heart block and maternal systemic lupus erythematosus. Br. Med. J. 1:1235-1238.

17. Geggel, R. L., L. Tucker, and I. Szer. 1988. Postnatal progression from second- to third-degree heart block in neonatal lupus syndrome. J. Pediatr. 113:1049-1052.

18. Lee, L. A., W. L. Weston, G. G. Krueger, M. Emam, M. Reichlin, J. O.
Stevens, S. K. Surbrugg, A. Vasil, and D. A. Norris. 1986. An animal model of antibody binding in cutaneous lupus. Arthritis Rheum. 29:782-788.

19. Lee, L. A., K. K. Gaither, S. N. Coulter, D. A. Norris, and J. B. Harley. 1989. Pattern of cutaneous immunoglobulin $G$ deposition in subacute cutaneous lupus erythematosus is reproduced by infusing purified anti-Ro (SSA) autoantibodies into human skin-grafted mice. J. Clin. Invest. 83:1556-1562.

20. Behan, W. M. H., P. O. Behan, J. M. Reid, W. Doig, and J. Gairns. 1989. Family studies in congenital heart block associated with Ro antibody. Br. Heart J. 62:320-324.

21. Bilazarian, S. D., A. J. Taylor, D. Brezinski, M. C. Hochberg, T. Guarnieri, and T. T. Provost. 1989. High-degree atrioventricular heart block in an adult with systemic lupus erythematosus: the association of nuclear RNP (U1 RNP) antibodies, a case report, and review of the literature. Arthritis Rheum. 32:1170-1174.

22. Alexander, E., J. P. Buyon, T. T. Provost, and T. Guarnieri. 1992. AntiRo/SS-A antibodies in the pathophysiology of congenital heart block in neonatal lupus syndrome: an experimental model. Arthritis Rheum. 35:176-189.

23. Tan, E. M., A. S. Cohen, J. F. Fries, A. T. Masiat, D. J. McShane, N. F. Rothfield, J. G. Schaller, N. Talal, and R. J. Winchester. 1982. The 1982 revised criteria for the classification of systemic lupus erythematosus. Arthritis Rheum. 25:1271-1277.

24. Tan, E. M. 1982. Autoantibodies to nuclear antigens (ANA): their immunology and medicine. Adv. Immunol. 33:167-240.

25. Kurata, N., and E. M. Tan. 1976. Identification of antibodies to nuclear acidic antigens by counterimmunoelectrophoresis. Arthritis Rheum. 19:574-580.

26. Elkon, K. B., and P. W. Jankowski. 1985. Fine specificities of autoantibodies directed against the Ro, La, Sm, RNP, and Jo-1 proteins defined by two-dimensional gel electrophoresis and immunoblotting. J. Immunol. 134:38193824.

27. Lockshin, M. D., M. L. Druzin, S. Goei, T. Qamar, M. S. Magid, L. Jovanovic, and M. Ferenc. 1985. Antibody to cardiolipin as a predictor of fetal distress or death in pregnant patients with systemic lupus erythematosus. $N$. Engl. J. Med. 313:152-156.

28. Magsaam, J., A. E. Gharavi, A. P. Parnassa, H. Weissbach, N. Brot, and K. B. Elkon. 1989. Quantification of lupus anti-ribosome $P$ antibodies using a recombinant $\mathrm{P} 2$ fusion protein and determination of the predicted amino acid sequence of the autoantigen in patient's mononuclear cells. Clin. Exp. Immunol. 76:165-172.

29. Bradford, M. M. 1976. Rapid and sensitive method for the quantification of microgram quantities of protein utilizing the principle of protein-dye binding. Anal. Biochem. 72:248-254.

30. Masuda, O. M., G. M. Engel, and A. P. B. Moreira. 1987. Characterization of isolated ventricular myocytes: two levels of resting potential. J. Mol. Cell. Cardiol. 19:831-839.

31. Hamil, O. P., A. Marty, E. Neher, B. Sackmann, and F. J. Sigworth. 1981. Improved patch-clamp techniques for high-resolution current recording from cells and cell-free membrane patches. Pflüegers Arch. Eur. J. Physiol. 391:85100.

32. Giles, W. R., and Y. Imaizumi. 1988. Comparison of potassium currents in rabbit atrial and ventricular cells. J. Physiol. (Lond.). 405:123-145.

33. Harley, J. B., J. L. Kaine, O. F. Fox, M. Reichlin, and B. Gruber. 1985. Ro (SS-A) antibody and antigen in patient with congenital complete heart block. Arthritis Rheum. 28:1321-1325.

34. Cohen, N. M., and W. J. Lederer. 1988. Changes in the calcium current of rat heart ventricular myocytes during development. J. Physiol. 406:115-146.

35. Furuwaka, F., M. B. Lyons, L. A. Lee, S. N. Coulter, and D. A. Norris. 1988. Estradiol enhances binding to cultured human keratinocytes of antibodies specific for SS-A/Ro and SS-B/La: another possible mechanism for estradiol influence of lupus erythematosus. J. Immunol. 141:1480-1488.

36. Furukawa, F., M. Kashihara-Sawami, M. B. Lyons, and D. A. Norris. 1990. Binding of antibodies to the extractable nuclear antigens SS-A/Ro and SS-B/La is induced on the surface of human keratinocytes by ultraviolet (UVL): implications for the pathogenesis of photosensitive cutaneous lupus. J. Invest. Dermatol. 94:77-85.

37. Kim, Y. I., and E. Neher. 1988. IgG from patients with Lambert-Eaton Syndrome blocks voltage-dependent calcium channels. Science (Wash. DC). 239:405-408.

38. McCauliffe, D. P., E. Zappi, T.-S. Lieu, M. Michalak, R. D. Sontheimer, and J. D. Capra. 1990. A human Ro/SS-A autoantigen is the homologue of calreticulin and is highly homologous with onchocercal RAL-1 antigen and an aplysia "memory molecule." J. Clin. Invest. 86:332-335.

39. Sontheimer, R. D., D. P. McCauliffe, M. Michalak, J. D. Capra, and T.-S. Lieu. 1990. Cytoplasmic localization of calcium-binding 46 kD human Ro/SS-A antigen. Arthritis Rheum. 33(Suppl. 9):S74a. (Abstr.)

40. Rokeach, L. A., J. A. Haselby, J. E. Meilaf, R. J. T. Smeenk, T. R. Uhnasch, B. M. Greene, and S. O. Hoch. 1991. Characterization of the autoantigen calreticulin. J. Immunol. 147:3031-3039.

41. Lieu, T.-S., D. P. McCauliffe, and M. M. Newkirk. 1989. A major autoepitope is present on the amino terminus of the human Ro/SS-A polypeptide. $J$. Autoimmun. 2:367-374. 